\title{
Experimental Study and Numerical Simulation of Sediment Transport in a Shallow Reservoir
}

\author{
L.B.S. Souza ${ }^{1}$, H.E. Schulz ${ }^{2}$, S.M. Villela, J.S. Gulliver ${ }^{3}$ and L.B.S. Souza ${ }^{4}$ \\ ${ }^{1}$ Civil Engineering School-Federal University of Goias, Goiania, GO, 74605-220, Brazil \\ ${ }^{2}$ Department of Hydraulics and Sanitation-University of Sao Paulo, Sao Carlos, SP, 13566-590, Brazil \\ ${ }^{3}$ Department of Civil Engineering - University of Minnesota, South Minneapolis, MN, 55455, USA \\ ${ }^{4}$ Computer Science Department-Catholic University of Goias, Goiania, GO, 74605-010, Brazil \\ Email:leo_barra@yahoo.com
}

(Received February 1, 2009; accepted June 15, 2009)

\begin{abstract}
The prediction of sedimentation is an important aspect of reservoir planning and design. Such prediction can be supported by detailed analyses of flow patterns and sediment transport inside reservoirs, usually conducted through numerical simulation. This research compares laboratorial sedimentation experiments in a shallow reservoir and predictions using a 2D numerical model with depth-average Navier-Stokes equations and a sediment transport code. A number of sediment transport equations were tested, among which the Engelund and Fredsøe formulation better represented the measured data. Flows without sediment transport or without bed dunes could be simulated using Smagorinski's turbulence model, while flows with sediment occurring over dunes needed the use of a constant turbulent viscosity. The similarity obtained between experimental data and numerical results, for both flow pattern and sediment deposition, confirms that the models and numerical codes used in this work are useful for the analysis and prediction of reservoir sedimentation.
\end{abstract}

Keywords: Reservoir modeling, sediment transport, shallow flow, computational fluid dynamics.

\section{INTRODUCTION}

The study of sediment transport processes is important in the planning phase of reservoirs. Based on the analysis of probable rates of sedimentation, there are preventive and corrective procedures which can be taken to minimize sediment deposition and extend the useful lifetime of reservoirs.

Prediction of material volumes to be deposited over the years and their non-uniform distribution along the reservoir involves a detailed analysis of fluid and sediment motion inside the reservoir, typically performed with numerical modeling. Verification of numerical simulation is the main focus of this study, and the experimental results to be reproduced numerically were obtained in a laboratorial shallow reservoir. Successful simulation of the results of well controlled experiments provides verification that adds confidence to numerical simulation of sediment deposition rates in full-scale reservoirs.

\subsection{Numerical Modeling of Reservoir Sedimentation}

A number of codes and software applied in the study of reservoir morphology have been developed in universities, government agencies, private companies or through cooperation of them. These tools have been used to support decisions, even political, about reservoir operation and predictions of their useful lifetime.

Dhamotharan et al. (1981) utilized a one dimensional unsteady numerical model to establish the important reservoir sedimentation variables for trap efficiency as a Peclet number, using depth and turbulent diffusion coefficient, and a Courant number. Ziegler and Nisbet (1995) simulated 30 years of cohesive sediment transport (from 1961 to 1991) with the SEDZL model, in the Watts Bar reservoir - Tennessee, which is a part of the Tennessee Valley Authority reservoir system. Bathymetry data from 1946, 1951, 1956, 1961 and 1991, done in 64 cross-sections of the reservoir were used to calibrate the model. Although a quantitative comparison with the actual bathymetry resulted in an error of $46 \%$, the simulation was considered satisfactory by the authors. This software was also used in the study of fine sediment transport in other aquatic systems, such as Fox River - Wisconsin (Gailani et al. 1991), Pawtuxet River - Rhode Island (Ziegler e Nisbet 1994), and Lake Irie (Lick et al. 1994). 
A study with FLUVIAL-12 was developed by Chang et al. (1996) to analyze the efficiency of flushing operations in reservoirs along the North Fork Feather River, U.S.A.. The study pointed to a deficiency in electric energy generation due to sedimentation in the near future. The three-dimensional model CH3D-SED was described by Gessler et al. (1999). The model simulated non-cohesive sediment transport in open channels with an application in the project Deep Draft Navigation, in the Lower Mississippi River. Olsen (1999) applied the three-dimensional model SIIMM to predict sedimentation in the Kali Gandaki Hydropower Reservoir, Nepal. Results from a physical model built in scale 1:50 (12m long and $6 \mathrm{~m}$ wide) and from the numerical model estimated that the reservoir volume of 0.4 million cubic meters would be filled in a short period of time if flushing operations were not run. Other numerical models have been successfully applied to river and reservoir morphology, such as FAST3D at the University of Karlsruhe (Demuren 1991); HEC-6 from the U.S. Army Corps of Engineers (Nicklow and Mays 2000); and Delft3D, with application to Senbiri reservoir, Toshibetsu river, Japan (Sloff et al. 2004).

\subsection{Reservoir Morphology Modeling in Brazil}

Numerical modeling of reservoir morphology is still rare in Brazil, particularly for models with hydrodynamics and sediment transport in two or three dimensions. For one and quasi-two-dimensional models, there are some classical works, such as Alvim (1987) and Cogollo and Villela (1988), the latter based on the mathematical model of Lopes (1978), for the prediction of sedimentation in Urra II reservoir, Sinu River, Colombia.

The small number of simulations is related to the scarceness of concomitant and periodic measurements of water discharge, sediment transport and bathymetry in national reservoirs. These measurements are essential for the study of spatial distribution of sedimentation and its progress in time. The lack of field data makes the calibration of numerical models and validation of their results difficult or impossible. Therefore, for the present study, the sedimentation and bed load transport processes were carried out in a shallow reservoir built in the Environmental Hydraulics Laboratory at the University of Sao Paulo, Brazil, under controlled conditions of water and sediment discharge, and reproduced numerically. The validation of the numerical results, based on their comparison and agreement with the experimental results, would support the use of numerical tools for sediment transport in the analysis and prediction of reservoir sedimentation.

\section{Materials ANd Methods}

\subsection{Shallow Reservoir and PIV Laser Technique}

The shallow reservoir was built based on a device developed in Barbosa (1999) and Silva (2002) for studies of density currents. The walls are of Perspex, permitting the use of PIV laser measurements of flow patterns. Sand deposition was documented with pictures taken from different angles.
A view of the reservoir in operation, with a width of $1.5 \mathrm{~m}$ and length of $3.00 \mathrm{~m}$, is presented in Fig.1, together with a simplified sketch. Velocity measurements where conducted with the laser sheet crossing the side walls and a CCD camera positioned under the bed of the reservoir.

Two prismatic channels, $2.0 \mathrm{~m}$ long, $0.15 \mathrm{~m}$ wide and $0.25 \mathrm{~m}$ high, originally supplied water to the reservoir. The present experiments were conducted using only the left supply channel. The sand supply structure, with an elevated reservoir, had a volume of $0.40 \mathrm{~m} 3$ with its bottom positioned $1.50 \mathrm{~m}$ above the reservoir. A pressurized air system fed the channels with a constant sediment discharge of $0.002 \mathrm{~kg} / \mathrm{s}$.

The PIV technique could not be applied, evidently, during the sedimentation process. The images were taken with the CCD camera positioned beneath the reservoir, so the sand deposition did not permit the acquisition of flow images. Therefore, instantaneous and mean velocity fields were obtained in several reservoir regions during the water flow, before the addition of sand at the inlet. These fields contributed to the study of the relation of the initial flow and the beginning of sedimentation, while the reservoir geometry was not significantly changed by sand deposition. In this case, it was observed that the sediment was first carried following the recirculation pattern of the flow, but this pattern of movement was broken when the sand bed formed its "blunt head" at the entrance of the reservoir. Additionally, the initial measured velocity field was helpful in the validation of the initial simulated velocity field, fundamental for the beginning of the next step, the simulation of sediment transport and deposition.

The locations of the regions analyzed by laser were chosen in order to obtain an overview of initial flow pattern. Each squared region, with a $15 \mathrm{~cm}$-side, was located horizontally and $6 \mathrm{~cm}$ above the bed, with the water depth in the entire reservoir varying from $11,5 \mathrm{~cm}$ at the outlet weir to $12,5 \mathrm{~cm}$ at the inlet of the channel. Thus, the measured velocities probably did not match the depth-average velocities, but had the same order of magnitude in the shallow reservoir and gave a good representation of the initial flow pattern.

Some images of the laser equipment in operation are given in Fig.2. A sequence of three flow images and two velocity fields obtained in one of the 15 regions is presented in Fig.3. A particle illuminated by the laser sheet is followed by the arrow, to illustrate the flow. Further details of the construction of the reservoir and the use of PIV laser technique are presented in Souza et al. (2005).

\subsubsection{Experimental sedimentation}

The sedimentation process began after $30 \mathrm{~min}$ of water flow, for the establishment of steady flow regime, with $0.002 \mathrm{~m}^{3} / \mathrm{s}$ of discharge in the supply channel. The Reynolds number based on the water depth at inlet was $1.310^{4}$ and remained constant during the experiment. The mass discharge of sand with $\mathrm{d}_{50}$ equal to $0.12 \mathrm{~mm}$ 
was $2.0 \mathrm{~g} / \mathrm{s}$, which represented an upstream average concentration of $1 \mathrm{~g} / \mathrm{L}$ at the beginning of the channel, where the sand was released. The mean sediment volumetric concentration (volume of sediment/volume of liquid) in this position was of 0.00040 . The sedimentation process was run for $72 \mathrm{~h}$.

\subsection{Numerical Modeling}

The numerical simulation was conducted using MIKE21C (Olesen 1987; Talmon 1992), which uses mass and momentum equations reduced to $2 \mathrm{D}$ vertically integrated Navier-Stokes equations. Three-dimensional effects of secondary flows are kept in simplified form through the addition of a helical flow tool to the model, described by Vriend (1981). For sediment transport, a number of equations were tested, which is described in Souza (2006). The Engelund and Fredsøe (1976) equation best reproduced the experimental results.

\subsubsection{Hydrodynamic simulation}

The numerical grid was composed of 67,500 cells, $1 \mathrm{~cm}$ $\mathrm{x} 1 \mathrm{~cm}$, with a time step of $0.01 \mathrm{~s}$, which avoided numerical instability. The steady state regime was approached after $16 \mathrm{~min}$ and $40 \mathrm{~s}$ of flow, which justified the 30 minutes used in the experiments. The boundary conditions were upstream water discharge $\left(0.002 \mathrm{~m}^{3} / \mathrm{s}\right)$, and downstream water level (set to $0.113 \mathrm{~m}$, being $0.10 \mathrm{~m}$ for the spillway plus $0.013 \mathrm{~m}$ for the water above it). A sediment concentration of $1000 \mathrm{~g} / \mathrm{m}^{3}$ was set at the entrance of the supply channel.

The formulation of Smagorinsky (1963) was used for the turbulent viscosity in the first simulations. Manning coefficient $\mathrm{n}$ was set at $0.02 \mathrm{~s} / \mathrm{m}^{1 / 3}$, and the resistance imposed to the flow was constantly recalculated according to the Chezy parameter $\mathrm{C}=\mathrm{H}^{1 / 6} / \mathrm{n}$, in which $\mathrm{H}$ is the water depth. In a second stage of the simulations, a constant turbulent viscosity was used, as explained hereafter.

\subsubsection{Sediment transport simulation}

Based on the $0.01 \mathrm{~s}$ time step for the solution of the hydrodynamic equations, the time step for the sediment transport was defined as $10 \mathrm{~s}$, which means that the geometry of the reservoir was updated after each 1000 steps of hydrodynamics calculations.

To perform calculations, it was imposed that cells with water depths lower than $0.002 \mathrm{~m}$ were considered dried, and cells with water depths higher than $0.003 \mathrm{~m}$ were considered wet. This imposition defines whether cells are excluded or included in the computations, and has different values to avoid numerical instabilities.

The turbulent viscosity was calculated with Smagorinsky's model for the hydrodynamic simulation, which was run before the simulation of sedimentation. Despite attempts to run the sediment transport simulation with this turbulence model, the results that best represented the experimental data were achieved with a constant turbulent viscosity equal to $0.01 \mathrm{~m}^{2} / \mathrm{s}$. The ramifications of this decision are discussed later.

\section{ReSUlts AND Discussion}

\subsection{Flow Pattern in the Reservoir}

The results of flow simulations are presented together with the results of PIV measurements made in 15 regions within the reservoir. A simulated instantaneous velocity field is shown in Fig.4. Its color scale is the same used in Fig.3, and corresponds to the longitudinal component of velocity (horizontal component in the figures), in $\mathrm{m} / \mathrm{s}$. The instantaneous velocity fields obtained with the PIV laser in the 15 regions were averaged to obtain the mean flow fields (one for each region). The mentioned regions are superimposed on the simulated mean flow, in Fig.5.

In Fig.6, the measured and predicted mean velocities for the 15 regions are shown, with compatible values. The predicted velocities are in general higher than the measured velocities, a consequence of the free-slip condition at the vertical walls imposed by the 2D numerical model used here. The better agreement was attained for the regions which are crossed by the preferential flow from the inlet to the weir $(1,2,3,8$ and 12), and for regions farther from the corners of the vertical walls $(6,7,10,11$ and 14). The flow formed a large recirculation pattern, which was conveniently simulated, as shown in Figs. 4 and 5.

\subsection{Sedimentation}

The numerical simulation using Smagorinsky's turbulent model reproduced the first 4 hours of experimental sedimentation well. From that point on, however, the numerical turbulent viscosity did not reproduce the increase of turbulence intensity in the experiment, which was caused by the increasing flow velocity (decrease of cross section areas due to sedimentation) and the flow over sand dunes. In the simulations, sedimentation is modeled without the details of the dunes. So, the numerical turbulent intensity increases only due the increase of velocity without taken into account the form drag of the dunes.

To overcome this difficulty, simulations were run with a higher and constant turbulent viscosity, set at $0.01 \mathrm{~m}^{2} / \mathrm{s}$, during the sedimentation period. This resulted in less agreement between observed and predicted sedimentation for the first 4 hours of experimentation. However, the simulation produced an improved representation of the reservoir for $5 \mathrm{~h}$ to $72 \mathrm{~h}$, which is more representative of the sedimentation process under consideration. The value of $0.01 \mathrm{~m}^{2} / \mathrm{s}$ is of the same order of magnitude of the product between the mean velocity and depth in the inlet of the reservoir (in the present case, $0.013 \mathrm{~m}^{2} / \mathrm{s}$ ), which may be used as a first choice to scale viscosity to simulate reservoir sedimentation using this code. Comparisons of experimental results and theoretical predictions of flows with constant turbulent viscosity are shown by Janzen et al. (2003) and Schulz and Chaudhry (1998). More general theoretical solutions can be found in Schulz et al. (2005). Numerical simulations involving sedimentation and turbulence are presented, for example, by Razmi et al. (2008). 
As mentioned, the flow pattern obtained for water without sediment was used as initial condition for the constant turbulent viscosity calculations. The flow pattern obtained for the constant turbulent viscosity (Fig.7) may be compared to the one obtained using Smagorinsky's model (Fig.4). The higher turbulent viscosity caused higher divergence of the stream lines at the entrance of the reservoir and helped to form a rounder and more regular sediment transport front, such as the one observed in laboratory.

A plain view of the reservoir bed before sedimentation is shown in Fig.8. Cross sections from 1 to 4, used to compare measured and predicted sediment profiles, are also shown in this figure. The development of the simulated sedimentation is shown in the following figures, together with images of the real situations, to permit immediate comparison.

A plain view of the simulation results after $10 \mathrm{~h}$ of sediment transport and deposition is given in Fig.9. The simulation shows a mean sand depth around $7.5-9.0 \mathrm{~cm}$ high for $x$ between 1.5 and $2.0 \mathrm{~m}$ (in the first $0.5 \mathrm{~m}$ of the reservoir). For $x$ between 2.0 and $2.5 \mathrm{~m}$, the mean sand level rises up to around $10.0 \mathrm{~cm}$, which is confirmed by the height of the dunes observed in the longitudinal vertical view. From $1.0 \mathrm{~m}$ to $1.5 \mathrm{~m}$, the mean sand depth decreases in the experiment as well as in the simulation, although more smoothly in the latter. Lines linking the simulation plain view to the experimental longitudinal vertical view are introduced in Fig.9, to facilitate this comparison.

After 20 hours, both the simulated and the experimental results showed an elevated bed level with a round shaped front. A steep slope (at the contour of the sand deposition) was observed in the transversal direction, while a smoother slope was observed in the longitudinal direction of the reservoir. The similarity between simulation and experiment can be seen in Fig.10.

During the period from 20 to 50 hours the sediment transport expanded the dimensions of the elevated bed inside the reservoir, but the round shape and its height did not undergo substantial change. The slope around the sand deposit became smoother in the simulation than in the experiment. The level of the sand bed in the supply channel rose slightly as a consequence of the higher resistance to the flow imposed by the volume of sand deposited in the reservoir. It also caused a small elevation of water surface in the channel. Simulation and experiments indicated a similar behavior.

After 50h, the simulated elevated bed expanded in the transversal direction to a greater extent than that observed in the experiment. In addition, the bed presented a lower expansion in the longitudinal direction. The slopes remained smoother in the simulation. The general characteristics of the experiment, however, were still maintained by the simulation, as seen in Fig.11.

For the last 20 hours, the simulated sand bed again expanded primarily in the longitudinal direction, better representing the experiment. The final situation after
$72 \mathrm{~h}$, illustrated in Fig.12, presents a relatively more irregular shape and smoother slopes for the simulation. The higher spread of sand, in comparison to the experiment, implied a smaller area of flat elevated bed. In spite of this difference, the simulation presented a round shaped and considerably large and flat region of sedimentation, representative of the experimental result.

Fig.12 presents a three-dimensional view of the simulation after $72 \mathrm{~h}$, for which the level scale on the right considers the bottom of the reservoir as the reference level. It can be seen that, close to the inlet, a preferential flow way was formed (lower bed levels close to the inlet), observed in both the experiment (see erosion paths in Fig.12) and the simulation.

\subsubsection{Comparison of cross-sections}

Although the general results are adequate, a more refined comparison was made to highlight the remaining differences between simulation and observation. Bed heights were measured in four crosssections, positioned as shown in Fig.8, and the results after $72 \mathrm{~h}$ of experiment are shown in Fig. 13.

Sections 1, 2 and 3 presents good superimposition of numerical and experimental results. The divergence between both results should be considered significant in section 4 . The surface of the sand bed in the laboratory is more regular and flat than that obtained in the simulation. Also the measured slope is almost the same around the entire border, while the simulation shows different slopes for different positions.

The volume of sand deposited in the experiment and in the simulation was also calculated, showing that the simulation deposited around $13 \%$ less volume than that observed. A higher loss of material through the spillway in the simulation is the most probable cause of this difference.

\section{Conclusion}

Hydrodynamic simulations using Smagorinsky's turbulence model reproduced the flow pattern in the reservoir without sedimentation, when compared with the data obtained by PIV laser velocimetry. However, during the sedimentation process, the increase in turbulent diffusion caused by the formation of dunes in the experiment was not captured by the simulation. This occurred because the model is not completely threedimensional, furnishing average sedimentation and deposition without detailing the shape of the dunes. As a consequence, simulations using Smagorisky's model run well only while no high dunes were present, that is, for the first 4 hours of experiment. A constant turbulent viscosity of $0.01 \mathrm{~m}^{2} / \mathrm{s}$ was found to provide an acceptable simulation of sediment deposition. The high diffusion of momentum, expressed by the turbulent viscosity, produces an average flow which forms divergent stream lines at the entrance of the reservoir. The sand is transported mainly by advection, and the simulated form of the sand bed reproduced the observed form in the reservoir. 
The satisfactory agreement between experimental data and simulated results justifies the use of the models and numerical procedures of the present study, showing that they are useful tools for the analysis and prediction of reservoir sedimentation.

\section{ACKNOWLEDGEMENTS}

The authors do not have any propriety and financial interest in any product or company cited in this manuscript. The authors are indebted to CAPES (process 2201/06-2) and FINEP (process 23.01.0606.00).

\section{REFERENCES}

Alvim, A.M. (1987). Modelo matemático bidimensional de assoreamento em reservatórios. (2-D mathematical model for reservoir sedimentation) M.Sc. dissertation, Engineering School of Sao Carlos - University of Sao Paulo, Sao Carlos, Brazil (in Portuguese).

Barbosa, A.A. (1999). Correntes de densidade em reservatórios. (Density currents in reservoirs) $\mathrm{PhD}$ thesis, Engineering School of Sao Carlos University of Sao Paulo, Sao Carlos, Brazil (in Portuguese).

Chang, H.H., L.L. Harrison, W. Lee and S. Tu (1996). Numerical modeling for sediment-pass-through reservoirs. Journal of Hydraulic Research 122(7).

Cogollo, P.R.J. and S.M. Villela (1988). Mathematical model for reservoir silting. Proceedings of the Porto Alegre Symposium of Sediment Budgets, IAHS Publication, Porto Alegre, Brazil.

Dhamotharan, S., J.S. Gulliver and H.G. Stefan (1981). Unsteady One-Dimensional Settling of Suspended Sediment. Water Resources Research 17(4), 1125 1132 .

Demuren, A.O. (1991). Development of a mathematical model for sediment transport in meandering rivers. Report. no. 693, Institute for Hydromechanics, University of Karlsruhe, Karlsruhe, Germany.

Engelund, F., and J. Fredsøe (1976). A sediment transport model for straight alluvial channels. Nordic Hydrology 7(5).

Gailani, J., C.K. Ziegler and W. Lick (1991). Transport of suspended solids in the Lower Fox River. Journal of Great Lakes Reservoirs 17(4), 479-494.

Gessler, D., B. Hall, M. Spasojevic, F. Holly, H. Pourtaheri and N. Raphelt (1999). Application of 3D mobile bed, hydrodynamic model. Journal of Hydraulic Engineering 125(7).

Janzen, J.G., L.B.S. Souza and H.E. Schulz (2003). Kinetic energy in grid turbulence: comparison between data and theory. Journal of the Brazilian Society of Mech. Sci. and Eng. 25(4),437-351.

Lick, W., J. Lick and C.K. Ziegler (1994). The resuspension and transport of fine-grained sediments in Lake Irie. Journal of Great Lakes Reservoirs 20(4), 599-612.

Lopes, S.J.L. (1978). Mathematical modeling of sediment deposition in reservoirs. Hydrology Papers, Colorado State University, Fort Collins, Colorado, July.

Nicklow, J.W. and L.W. Mays (2000). Optimization of multiple reservoir networks for sedimentation control. Journal of Hydraulic Engineering 126(4).

Olesen, K.W. (1987). Bed topography in shallow river bends. Report 87-1, Faculty of Civil Engineering, Delft University of Technology, Netherlands.

Olsen, N.R.B. (1999). Two-dimensional numerical modelling of flushing processes in water reservoirs. Journal of Hydraulic Research 37(1).

Razmi, A., B. Firoozabadi and G. Ahmadi (2008). Experimental and numerical approach to enlargement of performance of primary settling tanks. Journal of Applied Fluid Mechanics 2(1), 112

Schulz, H.E. and F.H. Chaudhry (1998). Uma aproximação para turbulência gerada por grades oscilantes (An approximation for turbulence generated by oscillating grids), Proceedings of the First Spring School of Transition and Turbulence, COPPE, Brazil, 1, 181-194 (in Portuguese).

Schulz, H.E., J.G. Janzen and K.O.S. Souza (2005). Theoretical solutions for turbulent flows within the scenario of the k/ $\varepsilon$ model. Air Pollution XIII, WIT transactions on Ecology and the Environment, 82, WIT Press, 97-106.

Silva, S.V. (2002). Características de escoamentos decorrentes de diferenças de densidades. (Characteristics of flows caused by density currents) $\mathrm{PhD}$ thesis, Engineering School of Sao Carlos - University of Sao Paulo, Sao Carlos, Brazil (in Portuguese).

Sloff, C.J., H.R.A. Jagers and Y.K. Kitamura (2004, June). Study on the channel development in a wide reservoir. Proceedings of the 2nd International Conference on Fluvial Hydraulics, River Flow, Napels, Italy, 811-819.

Smagorinsky, J. (1963). General circulation experiment with the primitive equations. Monthly Weather Review 91(3), 99-164.

Souza, L.B.S., S.S. Venâncio, J.E. Alamy Filho, S.M. Villela and H.E. Schulz (2005, November). Construçao de uma armadilha de sedimentos em laboratório e análise do escoamento de água em 
L.B.S. Souza et al. / JAFM, Vol. 3, No. 2, pp. 9-21, 2010.

seu interior com uso de velocimetria a laser (Building a sand trap in laboratory scale and measuring the flow using Laser velocimetry), 16th Simpósio Brasileiro de Recursos Hídricos, Joao Pessoa, Brazil (in Portuguese).

Souza, L.B.S. (2006). Estudo experimental e modelagem numérica do escoamento e do assoreamento em uma armadilha de sedimentos. (Experimental study and numerical simulation of the flow and sedimentation in a sand trap), $\mathrm{PhD}$ thesis, Engineering School of Sao Carlos University of Sao Paulo, Sao Carlos, Brazil (in Portuguese).

Talmon, A.M. (1992). Bed topography of river bends with suspended sediment transport. Thesis, Delft University of Technology, Netherlands.

Vriend, H.J. (1981). Steady flow in shallow channel bends. Communication on Hydraulics 81-3, Department of Civil Engineering, Delft University of Technology, Netherlands.

Ziegler, C.K. and B.S. Nisbet (1994). Fine-grained sediment transport in Pawtuxet River, Rhode Island. Journal of Hydraulic Engineering 120(5), 561-576.

Ziegler, C.K. and B.S. Nisbet (1995). Long-term simulation of fine-grained sediment transport in large reservoir. Journal of Hydraulic Engineering 121(11). 

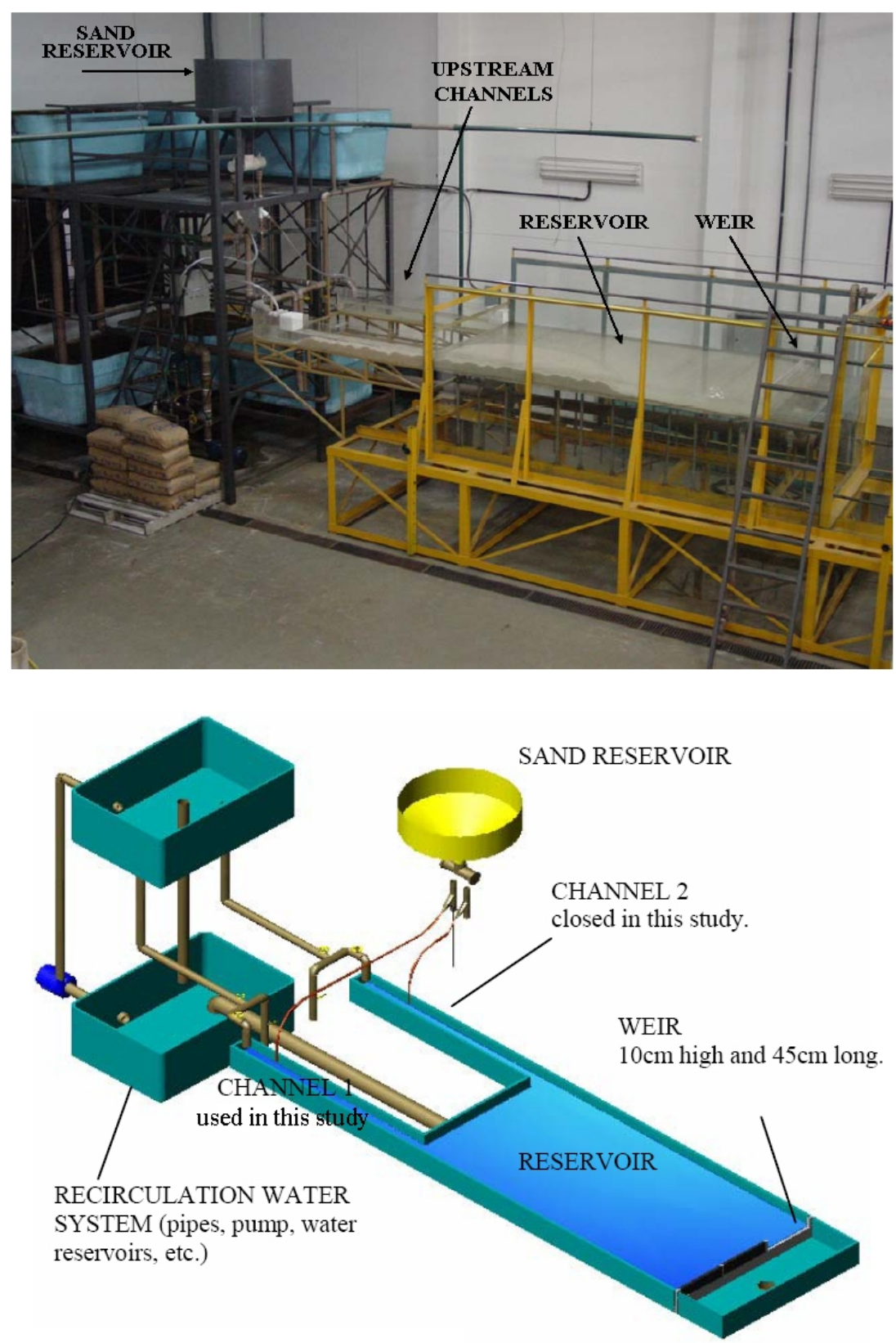

Fig.1. Above: view of the reservoir. Below: simplified sketch of the reservoir. 

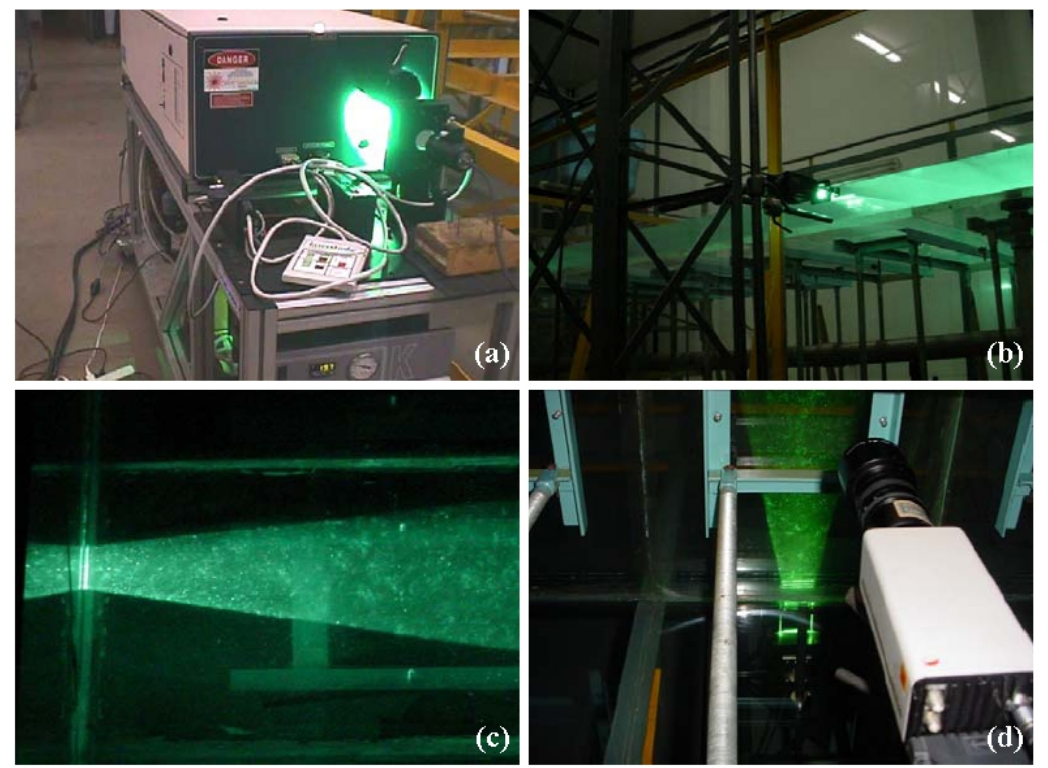

Fig.2. Laser equipment in operation. (a) The $20 \mathrm{~W}$ laser source. (b) Laser sheet applied through a lateral wall of the reservoir. (c) Plain view of the laser sheet in the reservoir. (d) CCD camera positioned beneath the reservoir bed. The camera was connected to a computer, for the analysis of images and calculus of instantaneous and mean velocity fields.
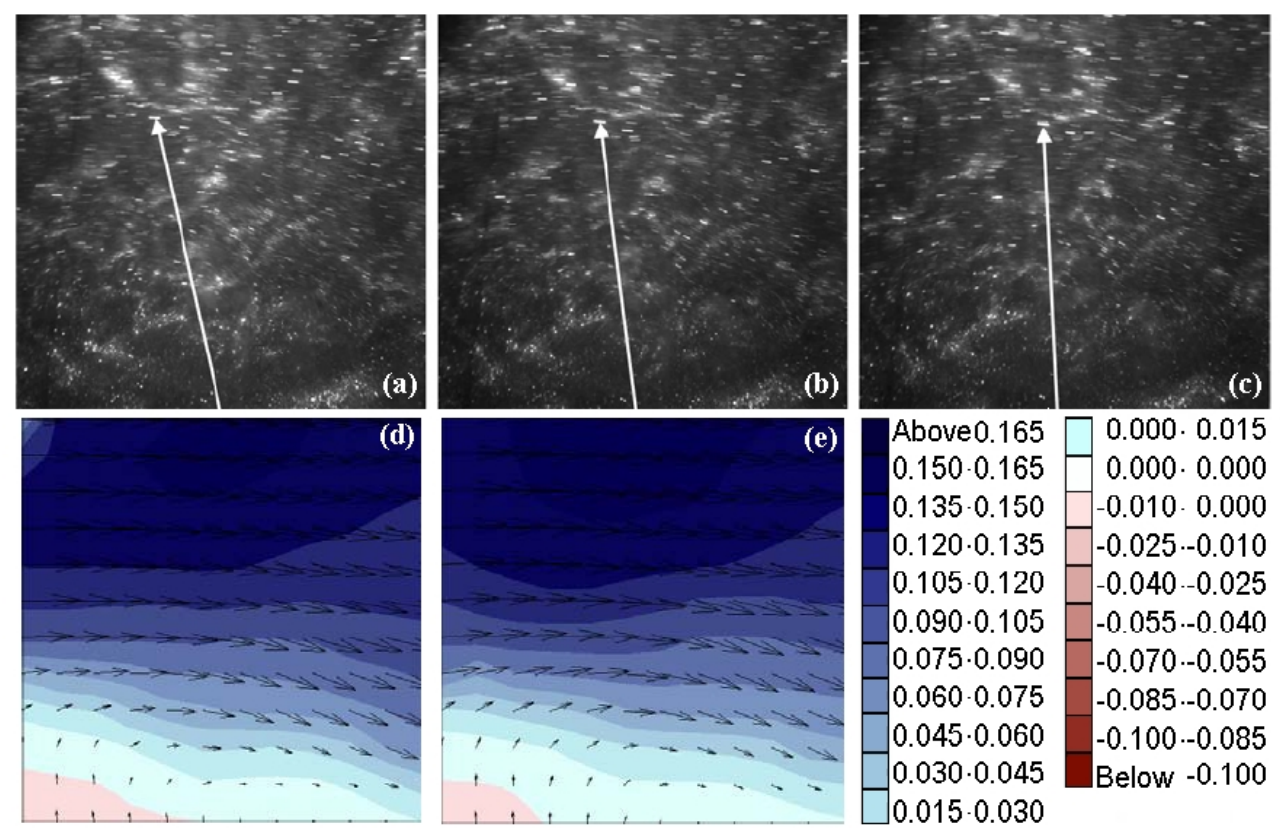

Above 0.165

$0.150 \cdot 0.165$

$0.135 \cdot 0.150$

$0.120 \cdot 0.135$

$0.105 \cdot 0.120$

$0.090 \cdot 0.105$

$0.075 \cdot 0.090$

$0.060 \cdot 0.075$

$0.045 \cdot 0.060$

$0.030 \cdot 0.045$

$0.015 \cdot 0.030$
$0.000 \cdot 0.015$

$0.000 \cdot 0.000$

$-0.010 \cdot 0.000$

$-0.025 \cdot-0.010$

$-0.040-0.025$

$-0.055 \cdot-0.040$

$-0.070 \cdot-0.055$

$-0.085-0.070$

$-0.100 \cdot-0.085$

Below - 0.100

Fig.3. A sequence of flow images is shown in (a), (b) and (c). The arrows show the same particle in the sequence. (d) and (e) are instantaneous flow fields obtained with the previous pictures. Color scale is for the $x$ velocity component in $(\mathrm{m} / \mathrm{s})$ (horizontal axis in this figure). 


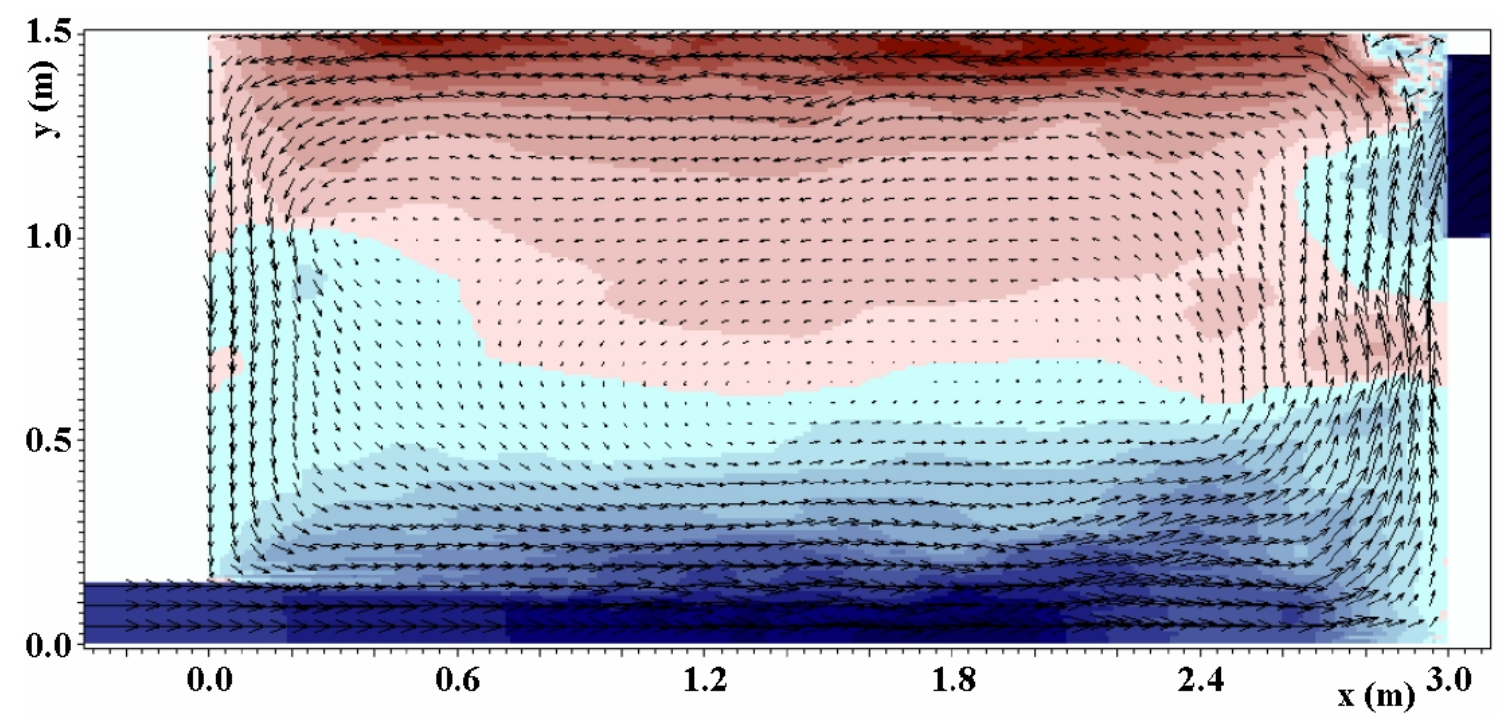

Fig.4. Instantaneous simulated field at 16 min $40 \mathrm{~s}$. The colors follow the same scale of Fig. 3, and corresponds to the "x component" of the velocity.

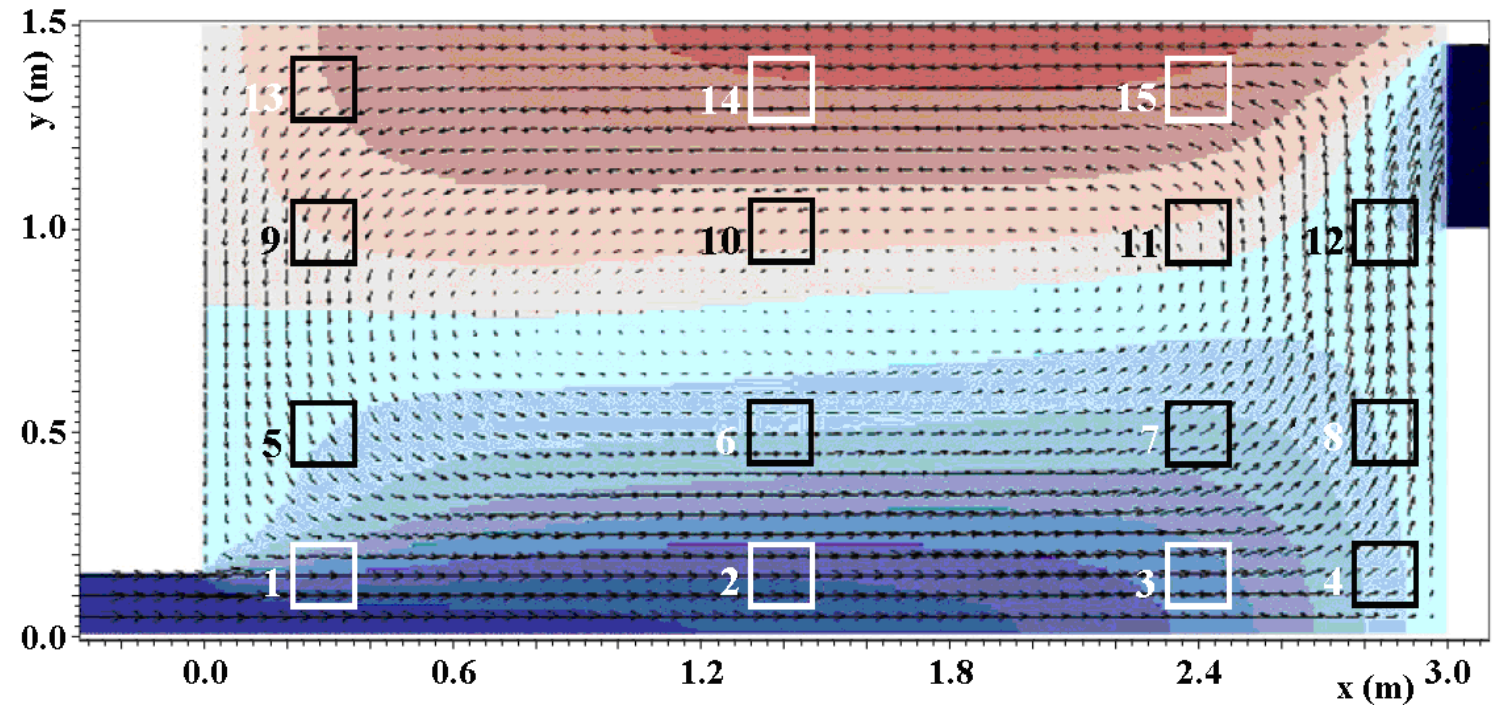

Fig.5. Predicted mean flow pattern, with PIV measurement regions identified by numbered squares. The colors correspond to the " $x$ component" of the velocity. Color scale in Fig.3. 


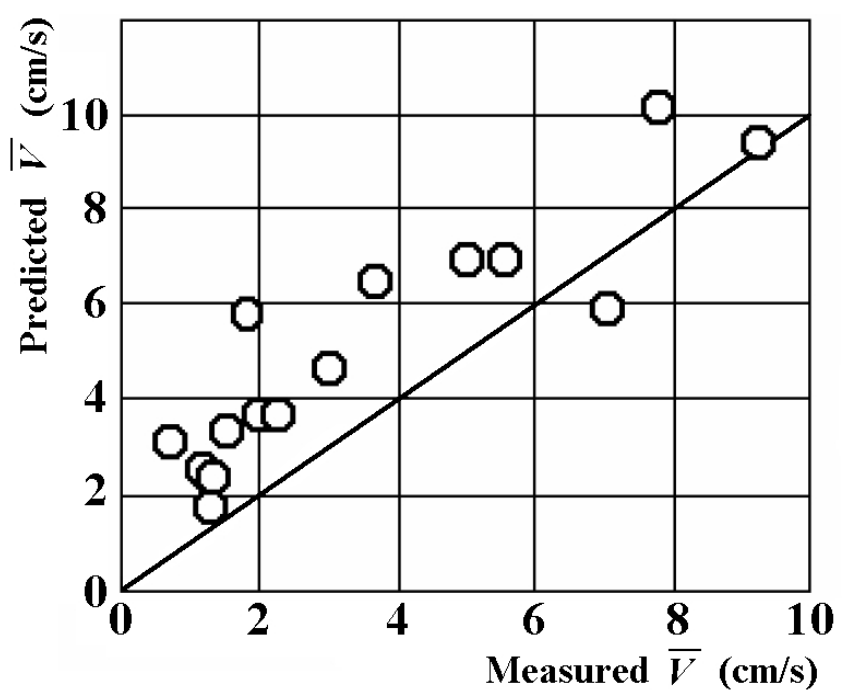

Fig.6. Predicted and measured velocities. $\bar{V}$ is the module of the mean velocity vector.

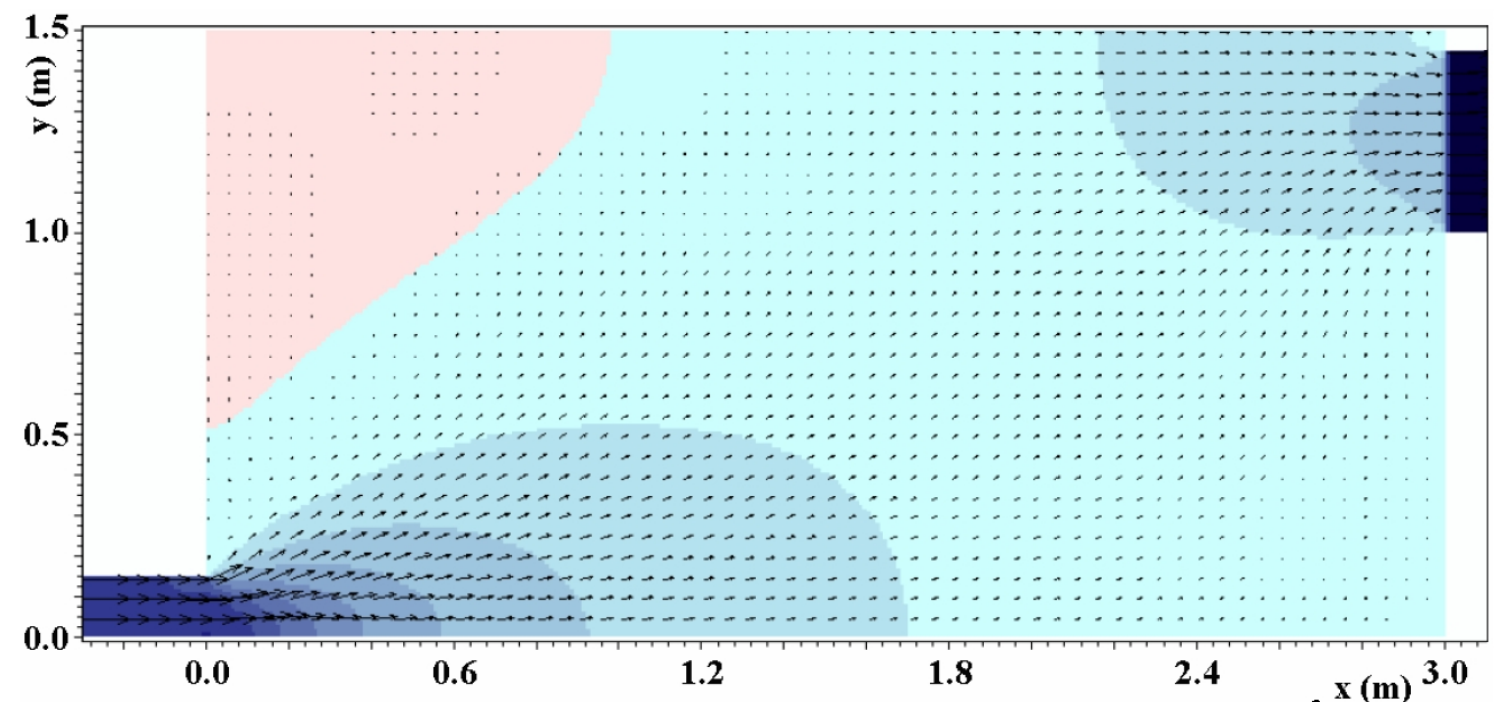

Fig.7. Instantaneous simulated field at $16 \mathrm{~min} 40 \mathrm{~s}$, with constant turbulent viscosity of $0.01 \mathrm{~m}^{2} / \mathrm{s}$. The colors follow the same scale of Fig. 3 , and corresponds to the "x component" of the velocity. 


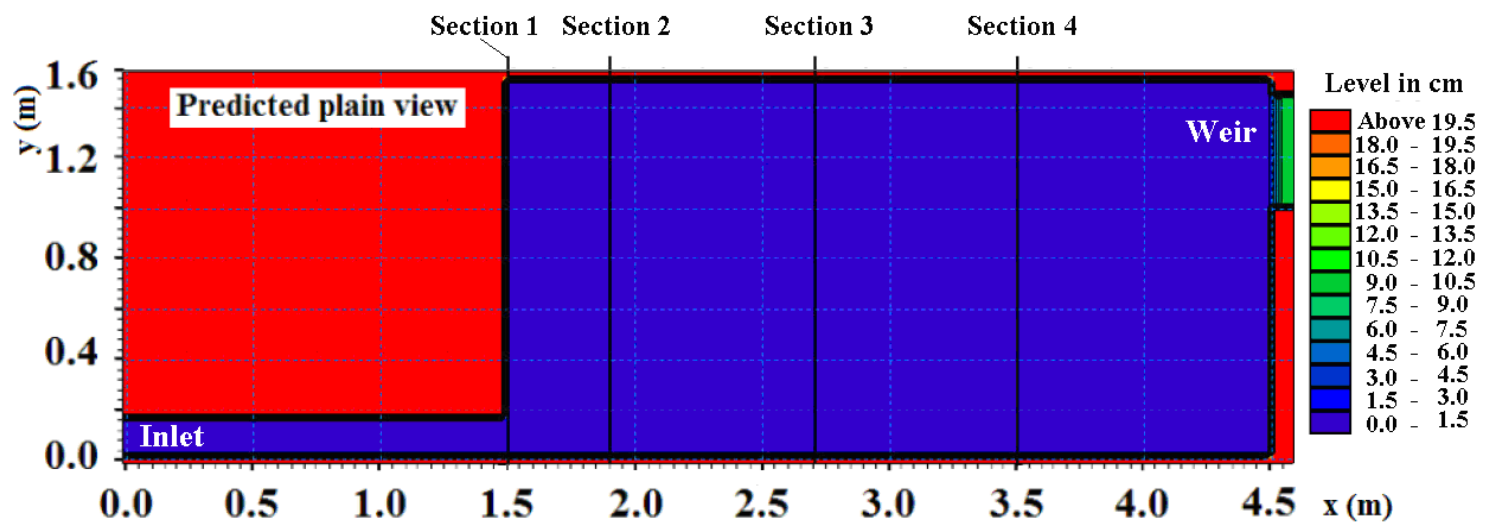

Fig.8. Sand reservoir before the sediment transport simulation. The color scale is also valid for Figs. 9, 10 and 11.

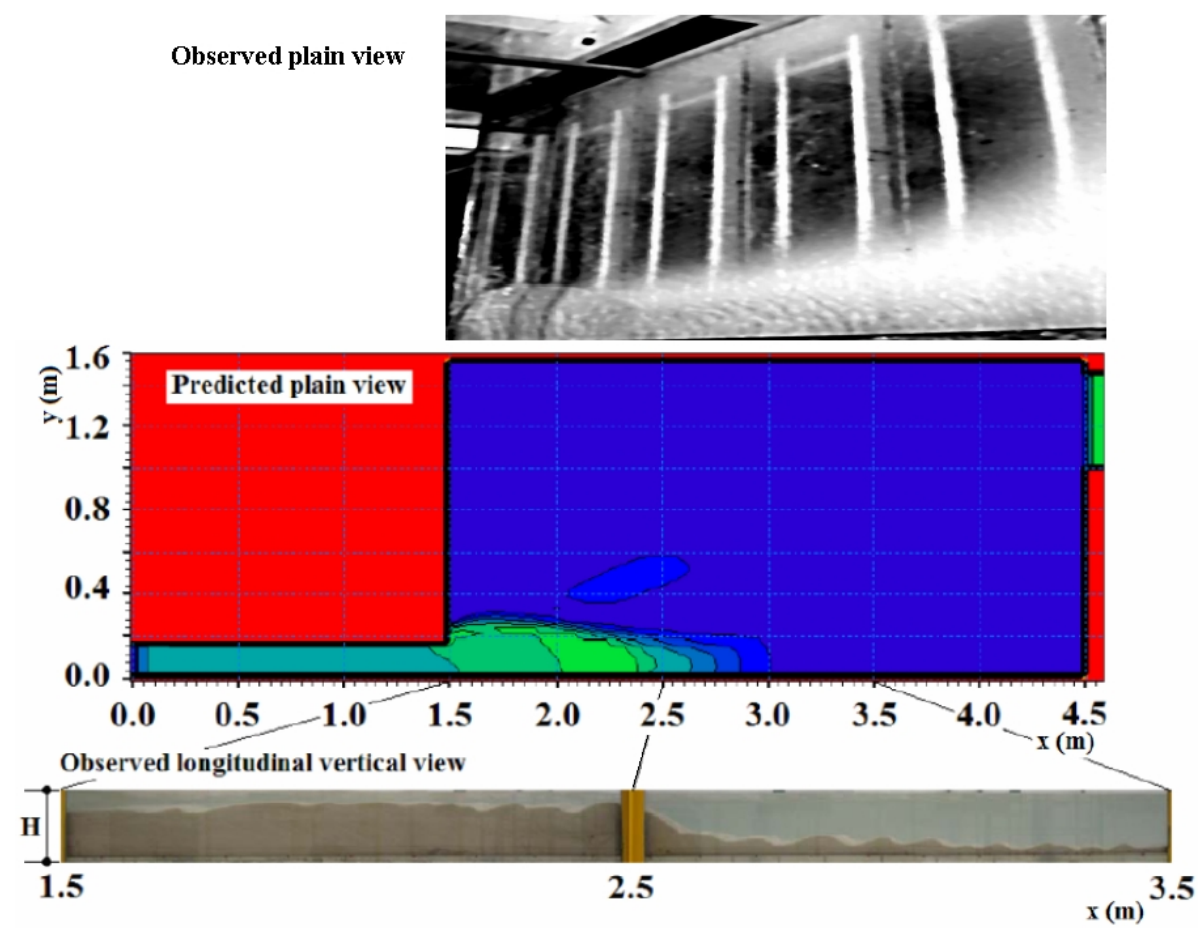

Fig.9. Predicted and observed sand bed after $10 \mathrm{~h} . \mathrm{H}$ is the position of the water surface, which varied from $11,5 \mathrm{~cm}$ to $12,5 \mathrm{~cm}$ above the horizontal bed. 


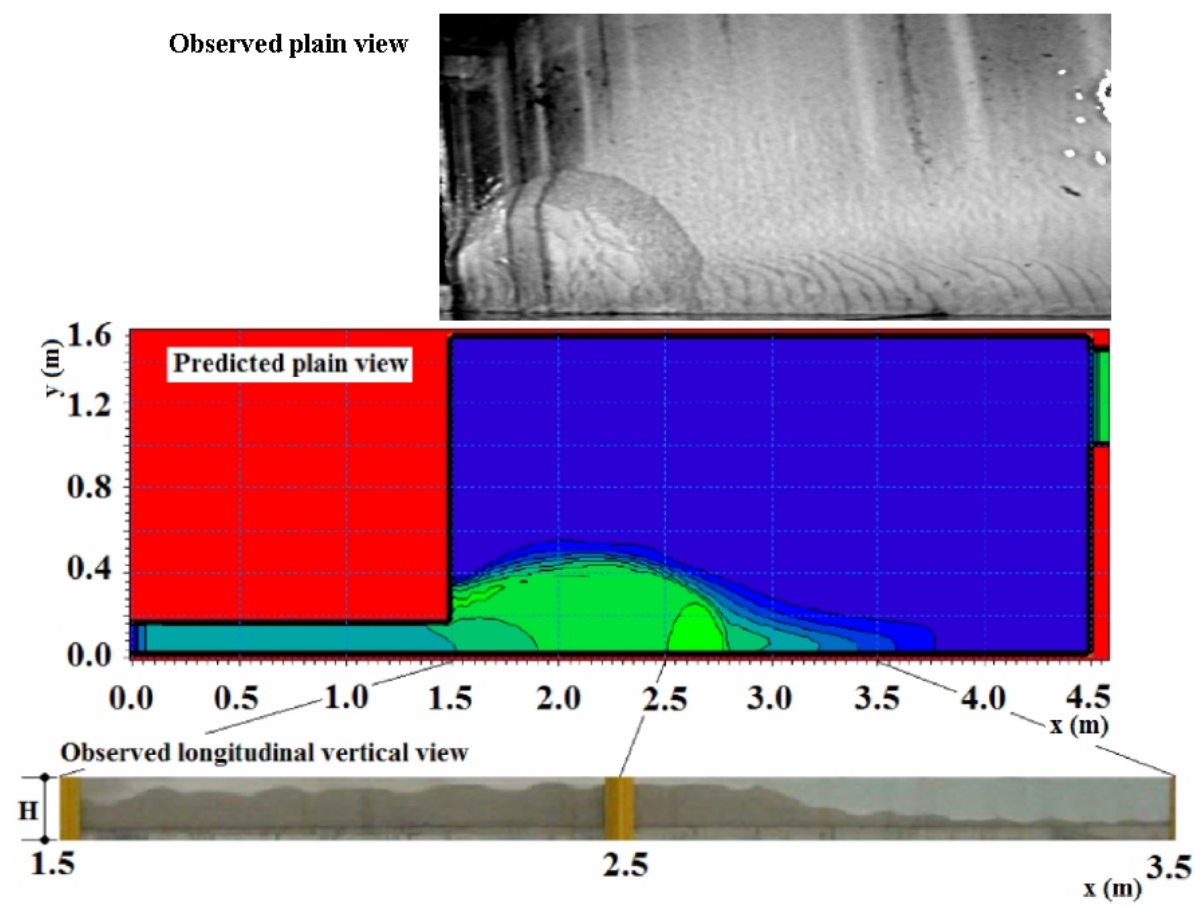

Fig.10. Predicted and observed sand bed after $20 \mathrm{~h} . \mathrm{H}$ is the position of the water surface.

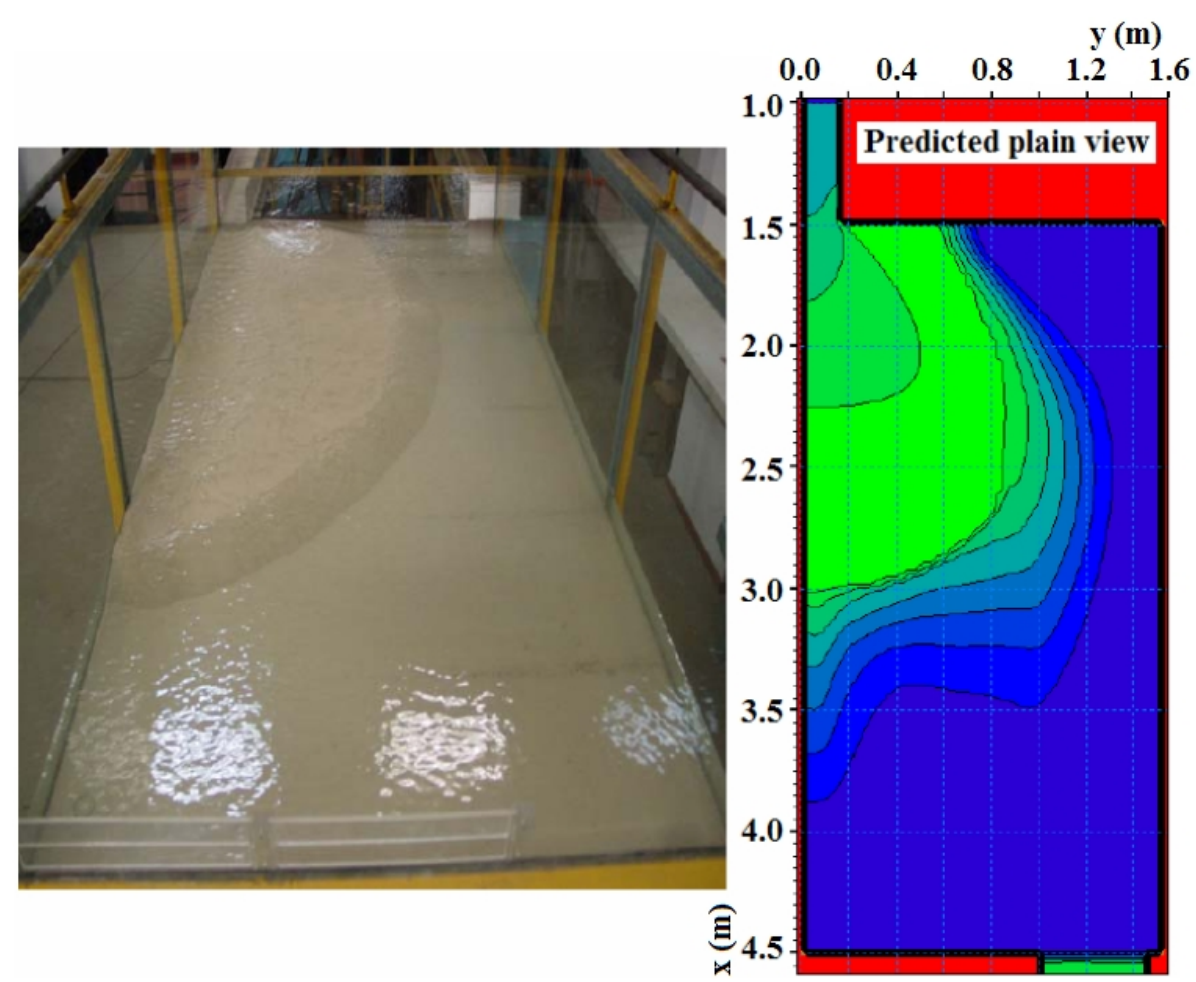

Fig.11. Observed and predicted sand bed after 50h. 

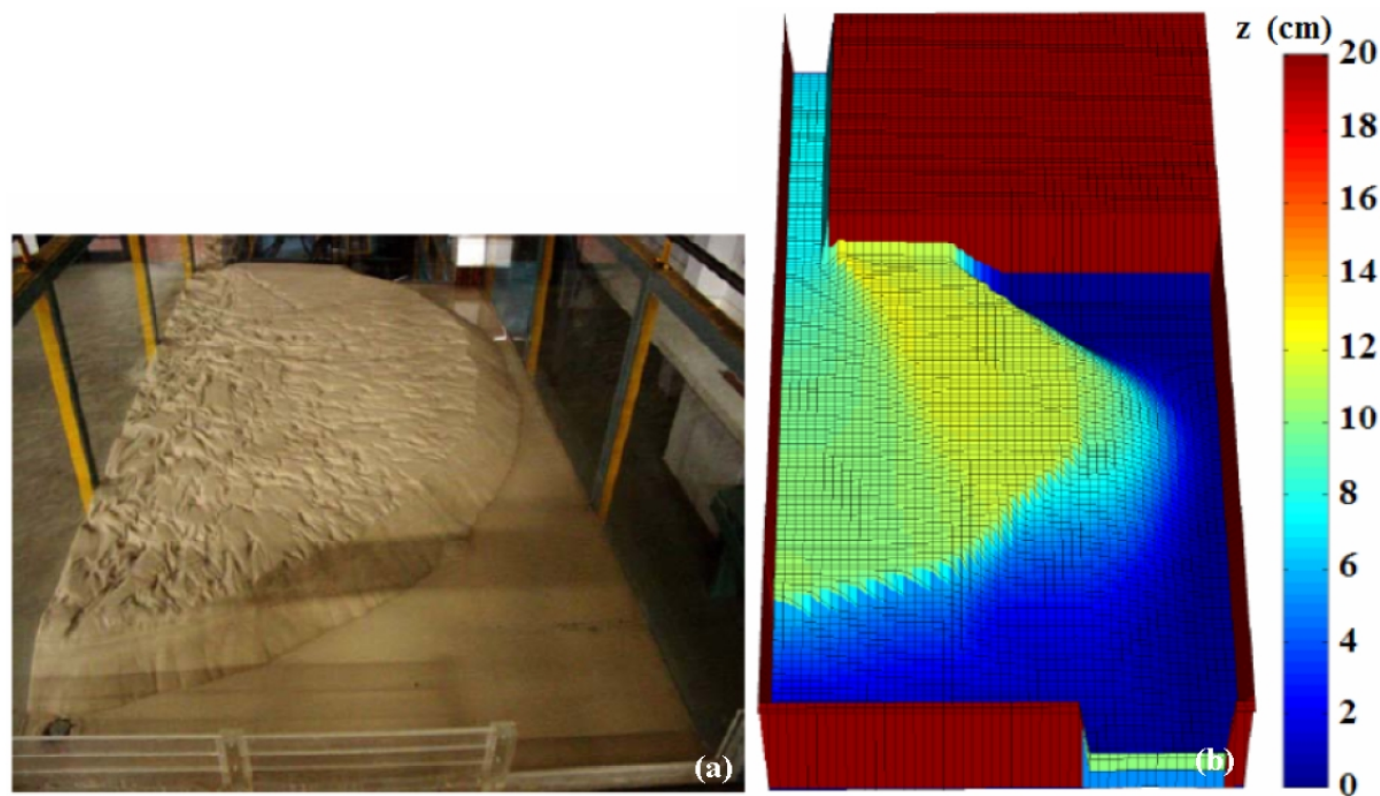

Fig.12. Observed (a) and predicted (b) sand bed after $72 \mathrm{~h}$. The color scale indicates $\mathrm{z}(\mathrm{cm})$, the height of the bed. The experiment (a) shows microchannels (lower bed level) concentrated closer to the left wall, which coincides with the position of the lower level of the simulated sand bed (b).
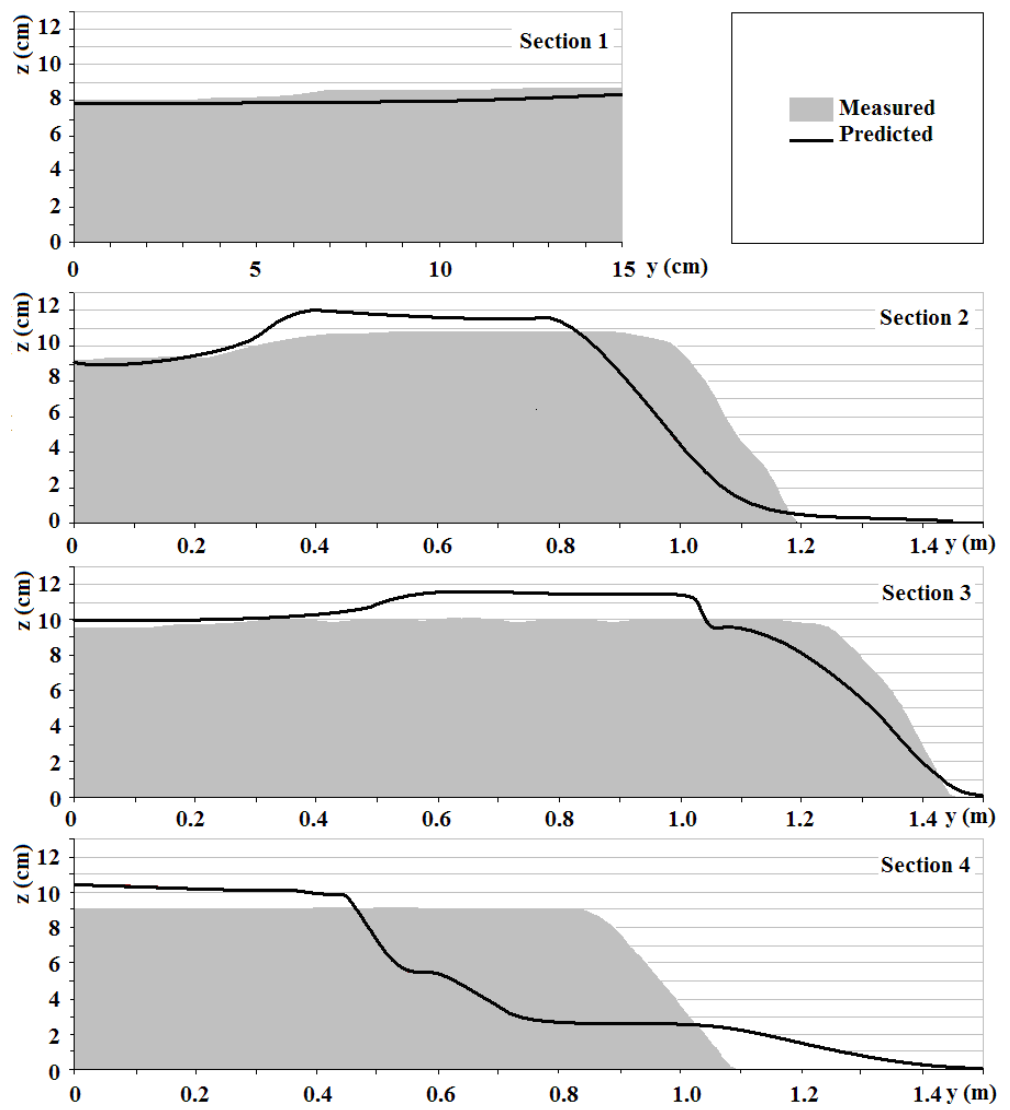

Figure 13 - Comparison of predicted and measured bed profiles in sections 1 through 4 after $72 \mathrm{~h}$. 